\title{
Pathophysiological and Clinical Approach to Cirrhotic Cardiomyopathy
}

\author{
Alida Páll, Árpád Czifra, Zsuzsanna Vitális, Mária Papp, György Paragh, Zoltán Szabó
}

University of Debrecen

Clinical Center

Department of

Gastroenterology

Debrecen, Hungary
Institute of Medicine,

\author{
Address for correspondence: \\ Mária Papp, MD, PhD \\ University of Debrecen \\ Clinical Center \\ Institute of Medicine, \\ Department of \\ Gastroenterology \\ Nagyerdei krt. 98, H-4032 \\ Debrecen, Hungary \\ papp.maria@med.unideb.hu
}

\begin{abstract}
Hyperdynamic circulation, systolic and diastolic left ventricular dysfunction and certain electrophysiological abnormalities have been associated with cirrhosis and known for a long time. These clinical features have been introduced as cirrhotic cardiomyopathy (CCM), which is characterized by blunted myocardial contractile responsiveness to physical, physiological and pharmacological stress. Importantly, cardiac dysfunction can be reversible and can improve due to effective medical treatment and also after liver transplantation. Echocardiography and electrocardiography are essential tools for recognizing the characteristic changes in the myocardial function and also the alterations in the electrophysiological properties of the heart. Laboratory markers are auxiliary modalities further aiding the establishment of the correct diagnosis. In this review, we aimed to collect the pathophysiological background and clinical characteristics of CCM with the intention of summarizing the current possibilities for the diagnosis establishment and treatment of this cardio-hepatic disorder.
\end{abstract}

Key words: liver cirrhosis - cardiomyopathy - heart failure - arrhythmias.

\begin{abstract}
Abbreviations: A: late diastolic transmitral peak flow velocity; ACE: angiotensin converting enzyme; ANP: atrial natriuretic peptide; ARB: angiotensin receptor blocker; BNP: brain natriuretic peptide; cAMP: cyclic adenosine monophosphate; CCM: cirrhotic cardiomyopathy; CGRP: calcitonin gene-related peptide; CO: carbon monoxide; DD: diastolic dysfunction; DT: deceleration time; E: early diastolic transmitral peak flow velocity; Ea: early diastolic velocity of the septal mitral annulus; EF: ejection fraction; MUGA: Multi Gated Acquisition Scan; NO: nitric oxide; NSBB: non-selective beta-blocker; pro-BNP: pro-brain natriuretic peptide; QTc: corrected QT interval; RAAS: renin- angiotensin aldosterone system; RALES: Randomized Aldactone Evaluation Study; suPAR: urokinase-type plasminogen activator receptor; TDI: Tissue Doppler Imaging; TIPS: transjugular intrahepatic portosystemic shunt; TNF-alpha: tumor necrosis factor-alpha.
\end{abstract}

Received: 29.04 .2014

Accepted: 10.06.2014

\section{INTRODUCTION}

Cirrhosis is associated with an increased risk for the development of cardiovascular diseases. Decreased systemic vascular resistance, increased cardiac output and abnormal myocardial contractile function are the characteristic features and likely to appear as consequences of cirrhosis. The functional and structural changes of the myocardium have been referred as cirrhotic cardiomyopathy (CCM), a slow progression myocardial dysfunction associated with cirrhosis [1]. Most importantly, this condition should not be confused with alcoholic cardiomyopathy where the underlying mechanism responsible for the structural and functional cardiac abnormalities is well defined [2]. In contrast to alcoholic cardiac disease, in the case of CCM any well-defined underlying provoking factor(s) can be identified; however, sometimes iron overload or alcohol consumption may worsen the already hampered structural and functional condition of the myocardium [3]. In CCM, left and right ventricular contractile function may decrease resulting in an altered responsiveness to physical, physiological and pharmacological activity, leading to the characteristic symptoms of heart failure [4]. Moreover, the disturbed ability for relaxation may lead to diastolic myocardial dysfunction or even diastolic heart failure. It is important to note that, based on the severity of diastolic heart 
function, patients are relatively asymptomatic. Nevertheless, regardless of clinical manifestation, diastolic heart failure is an independent risk factor for cardiovascular mortality in both symptomatic and asymptomatic patients [5]. Furthermore, diastolic dysfunction is an important underlying factor in the development of certain arrhythmias, especially in the genesis of atrial fibrillation [6]. In the case of CCM, appearance of electrophysiological abnormalities may result in an increased risk for the development of both atrial and ventricular rhythm disturbances. Fortunately, these abnormalities may be reversible after liver transplantation [7]. Cardiac dysfunction is considered to be multifactorial in chronic liver diseases. In the present review, we aimed to collect all the pathophysiological and clinical evidence that may help to understand the core of CCM in order to assist clinicians to come to a more exact diagnosis and establish a better treatment and care strategy for patients suffering from CCM in everyday clinical practice, surmounting complications, delaying progression and diminishing mortality.

\section{ROLE OF THE VASCULAR TONE IN THE GENESIS OF CIRRHOTIC CARDIOMYOPATHY}

Portal hypertension and altered liver function may play an important role in the change of intracardiac volume and pressure conditions in cirrhosis $[8,9]$. Variceal bleeding, concomitant anemia and the appearance of ascites are among the most important factors that contribute to the decreased right and left ventricular preload and afterload [10]. Reduction of central and arterial blood volumes in combination with arterial hypotension can lead to volume- and baroreceptor activation resulting in sodium-water retention [11]. The triad of systolic and diastolic dysfunction, hyperdynamic circulation and electrophysiological abnormalities are important clinical features of CCM. Arteriolar vasodilatation with increased cardiac output, low arterial blood pressure and decreased systemic vascular resistance eventuate the development of hyperdynamic syndrome in cirrhosis. Vasodilatation appears in the splanchnic area while vasoconstriction is present in the kidneys. These conditions are responsible for the decreased effective central blood volume [ 9 , 12]. High concentration of vasodilators and reduced sensitivity to vasoconstrictors play an important role in the genesis of vasodilatation in patients with cirrhosis known to be caused by various substances. Nitric oxide (NO), tumor necrosis factoralfa (TNF- $\alpha$ ), endocannabinoids, adrenomedullin, calcitonin gene-related peptide (CGRP), and carbon monoxide (CO) are the most important mediators in this field $[13,14]$. On the contrary, a concomitant activation of the sympathetic nervous system and the renin-angiotensin aldosterone system (RAAS) (noradrenaline, neuropeptide-Y, endothelin-1, angiotensin II, and vasopressin) has been observed [15, 16] (Fig. 1).

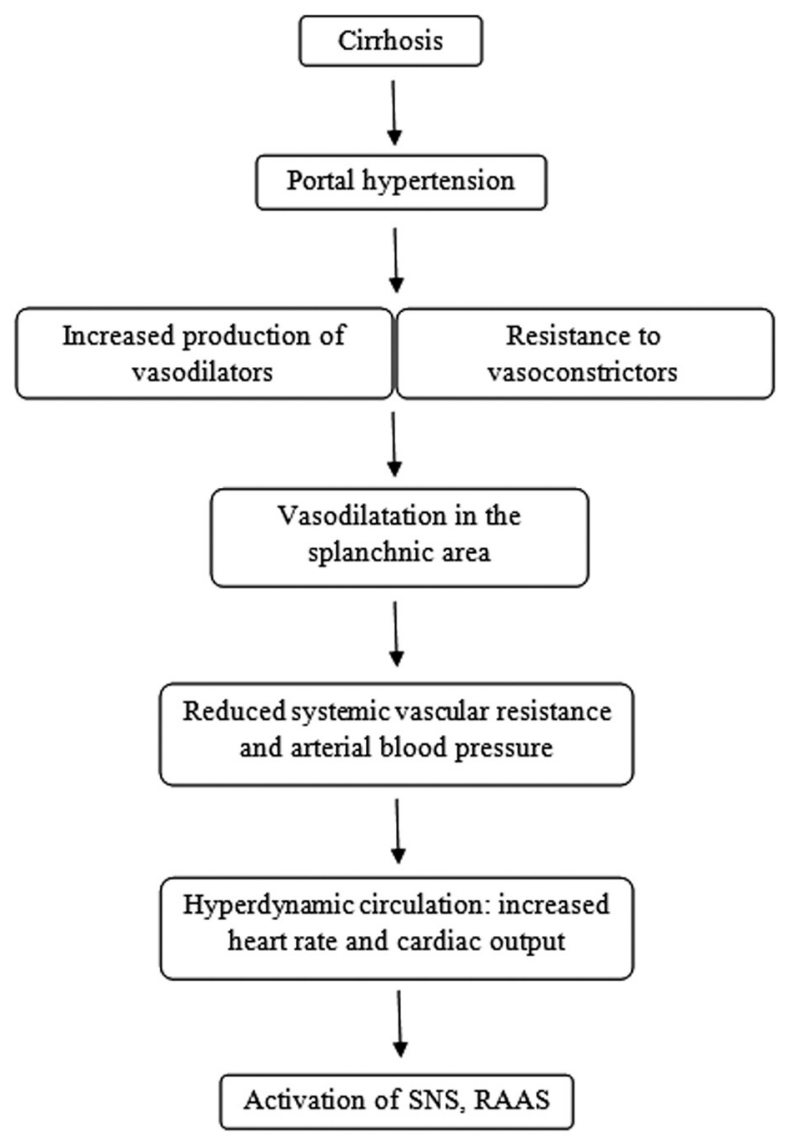

Fig. 1. Hyperdynamic circulation is caused by a pathophysiological cascade in patients with cirrhosis.

SNS: sympathetic nervous system; RAAS: renin angiotensin aldosterone system 


\section{MECHANISMS FOR ALTERED MYOCARDIAL FUNCTION}

\section{Systolic function}

In cirrhosis, myocardial dysfunction was found to be associated with the severity of liver disease. Systolic dysfunction, however, is mostly latent in this patient population. The circulatory dysfunction manifests itself as a hyperdynamic unloaded heart failure and cardiac output proves to be normal or increased at rest in most cases [17]. Reduction in myocardial function becomes overt under conditions of physical or pharmacological stress [18]. Latent systolic dysfunction becomes manifest during the normalization of arterial blood pressure [19]. Accordingly, clinical symptoms of systolic heart failure may evolve after liver transplantation or the placement of a transjugular intrahepatic portosystemic shunt (TIPS) [20]. Reduced left ventricular ejection fraction was found to be an important determinant for the development of the hepatorenal syndrome as well $[21,22]$. Several molecular abnormalities were identified as the background of systolic dysfunction in patients with cirrhosis. Alterations in the beta $(\beta)$-adrenergic signaling pathway result in a decreased density of $\beta$-receptors, reduction in G-proteins and consequently a decrease in the production of cyclic adenosine monophosphate (cAMP) [23]. Furthermore, due to the increased cholesterol content the fluidity of the myocardial cell membrane may alter and can impair the ion channel functions [24, 25]. Moreover, enhanced endocannabinoid signaling has a negative inotropic effect [14]. Additionally, NO overproduction exerts a toxic effect on the myocardium due to suppressed contractility and induced apoptosis [26]. As TNF- $\alpha$ is a major trigger mechanism of NO production, high level of this cytokine worsens the pathophysiological and clinical status [27].

\section{Diastolic function}

Decreased left ventricular relaxation is characterized by abnormal trans-mitral ventricular filling, increased atrial pressure and prolonged isovolumic relaxation [28]. The pathophysiological background of the diastolic dysfunction in cirrhosis is the increased stiffness of the myocardial wall, which is often caused by myocardial hypertrophy and fibrosis due to activation of the RAAS [29]. Subendothelial edema and increased interstitial collagen deposition play a further role in the decreased ability for relaxation $[2,8]$. Based on the severity of diastolic heart function, patients may be relatively asymptomatic. Diastolic dysfunction is an underlying factor in the development of atrial fibrillation where the pathomechanism is postulated to be due to an increased atrial volume load [6]. Despite these pathomechanisms, no convenient evidence can be evaluated on the relationship between cirrhosis and atrial fibrillation. Previously, Gundling et al reported the increased prevalence of atrial fibrillation in their cirrhotic cohort compared to the average population [30].

Nevertheless, regardless of clinical manifestation, diastolic heart failure is an independent risk factor for cardiovascular mortality in both symptomatic and asymptomatic patients [31].

\section{ELECTROPHYSIOLOGICAL ABNORMALITIES IN CIRRHOTIC CARDIOMYOPATHY}

Electrophysiological abnormalities occurring in cirrhosis comprise chronotropic incompetence, electromechanical uncoupling, and prolonged QT interval [32-34].

\section{Chronotropic incompetence}

In patients with chronotropic incompetence the sinus node is not able to respond to physiological and pharmacological stimuli. Furthermore, sympathetic overdrive conditions do not result in an adequate acceleration of atrial and ventricular rate. This is true even in the case of elevated plasma norepinephrine concentrations. This phenomenon may appear both in patients with alcoholic and non-alcoholic liver disease and correlates with the severity of cirrhosis $[2,35,36]$.

\section{Electromechanical uncoupling}

In the case of electromechanical uncoupling there is an asynchrony between electrical and mechanical systole that can lead to an altered contractile function of the ventricular myocardium resulting in congestive heart failure [33, 37]. Furthermore, the prevalence of electromechanical uncoupling is associated with the severity of liver disease depicted by Child-Pugh classification [32]. This abnormality has been demonstrated to be caused by receptor and post-receptor defects [34].

\section{QT interval and dispersion}

The QT interval represents the electrical depolarization and repolarization of the ventricular myocardium and it depends on the ventricular rate: the faster the heart rate the shorter it is [38]. Determination of the QT interval can aid the selection of the patient population with increased risk for the development of life threatening ventricular dysrhythmias [39]. The QT interval duration varies between leads on the standard surface electrocardiogram. The interlead difference of QT intervals is defined as QT dispersion, which is an index of the spatial dispersion of the ventricular recovery times, and can distinguish between myocardium that is homogeneous from myocardium that displays increased prolongation of repolarization [40]. Since these electrocardiographic markers can predict ventricular arrhythmias and sudden cardiac death they are considered to be among the most significant noninvasive parameters [41].

In patients with cirrhosis, the lengthening of the QT interval does not seem to be related to the etiology of the liver disease, and appears both in alcoholic and non-alcoholic subjects $[35,36]$. The prevalence of QT prolongation is high in patients with cirrhosis and increases with the severity of the liver disease. Accordingly, at least $60 \%$ of patients with endstage liver disease show this electrocardiographic abnormality [32]. Contraversely, Baik et al reported that sudden cardiac death is rare in cirrhosis, and torsades de pointes was described only in a few patients. Therefore, the clinical significance 
of QT prolongation in cirrhosis still remains to be clarified [42]. Prolongation of the QT interval may also worsen after TIPS insertion both in cirrhotic and non-cirrhotic portal hypertensive patients. Moreover, TIPS insertion was shown to be associated with an increased risk of heart failure [43]. The aforementioned electrophysiological changes appeared as a result of a combination of ion-channel dysfunction, plasma membrane abnormalities and $\beta$-adrenoceptor and post-receptor pathway defects.

Various ion channel defects in cirrhosis are now associated with the prolongation of the action potential of the myocardial cells, which results in the extension of ventricular systole or a prolonged QT interval $[44,45]$. The electrical properties of the myocardial cells largely depend on the duration of the monophasic action potentials, which are generated by special types of voltage gated ion channels placed in the myocardial cells' plasma membrane. These channels begin to open when the membrane potential passes a threshold value. During depolarization an inward flow of sodium ions appear, which results in a further rise in the membrane potential. Consequently, more channels will open (calcium channels), leading to a greater electric current across the myocardial cells' membrane. The polarity of the plasma membrane then turns to be reversed and the ion channels will rapidly become inactivated. Afterwards, an outward current of potassium ions (outward rectifier) will return the electrical transmembrane gradient to the resting state (repolarization) (Fig. 2). The plateau phase of the action potential depends on the balance between the efflux of potassium and the influx of calcium currents determining the repolarization time of the myocardial cell [46]. Impaired function of potassium channels in animal models of cirrhosis has been reported leading to a prolongation of the action potential, suggesting an increase in the transmural heterogeneity of repolarization [47].

Bacterial infections commonly appear in patients with cirrhosis. As the inflammation progresses cardio-depressant substances such as cytokines, endogenous cannabinoids, and nitric oxide are released [48]. The urokinase-type plasminogen activator receptor (suPAR) has recently been suggested to bear prognostic information [49]. These mediators may influence the activation of the inward calcium current leading to an increase in the duration of the monophasic action potential. Moreover, endothelin (which is elevated in cirrhosis) was shown to induce alterations in ion currents of myocardial cell preparations [50]. Also, increased bile acid levels (biliary cirrhosis) may modulate membrane fluidity causing the changes in ion channel activity and the alterations of $\beta$-adrenoceptor and G-protein function. Increased sympathetic nervous system activity in the presence of potassium channel defects may play a role in the genesis of inhomogeneous repolarization. Non-selective $\beta$-blockade may have a favorable effect on QT interval duration in patients with cirrhosis, which can be secondary to the improvement in hyperdynamic circulation and decreased portal pressure. In addition, the enhanced role of sympathetic activity in the genesis of myocardial dysfunction in cirrhosis was shown by Bernardi et al: a direct correlation between QTc and plasma norepinephrine was found that was absent during $\beta$-adrenergic blockade $[32,51]$.

However, Zambruni et al reported that chronic administration of a non-selective $\beta$-blocker was effective in reducing the QT interval only in patients with a prolonged baseline value. In patients with normal baseline values, the QT interval was not found to be changed by $\beta$-blockade. Accordingly, the exact role of chronic $\beta$-adrenoceptor blockade in the arrhythmogenesis in cirrhotic patients is not fully elucidated and needs further investigation [52].

\section{DIAGNOSIS}

\section{Clinical symptoms}

Since cardiac function is nearly normal at rest, the diagnosis of this disorder is not easy. In most cases this condition is well tolerated and may be asymptomatic for a long period of time, and it is often impossible to distinguish the clinical signs and complaints from those of the underlying disease. Most of the patients are diagnosed during the worsening of the liver disease

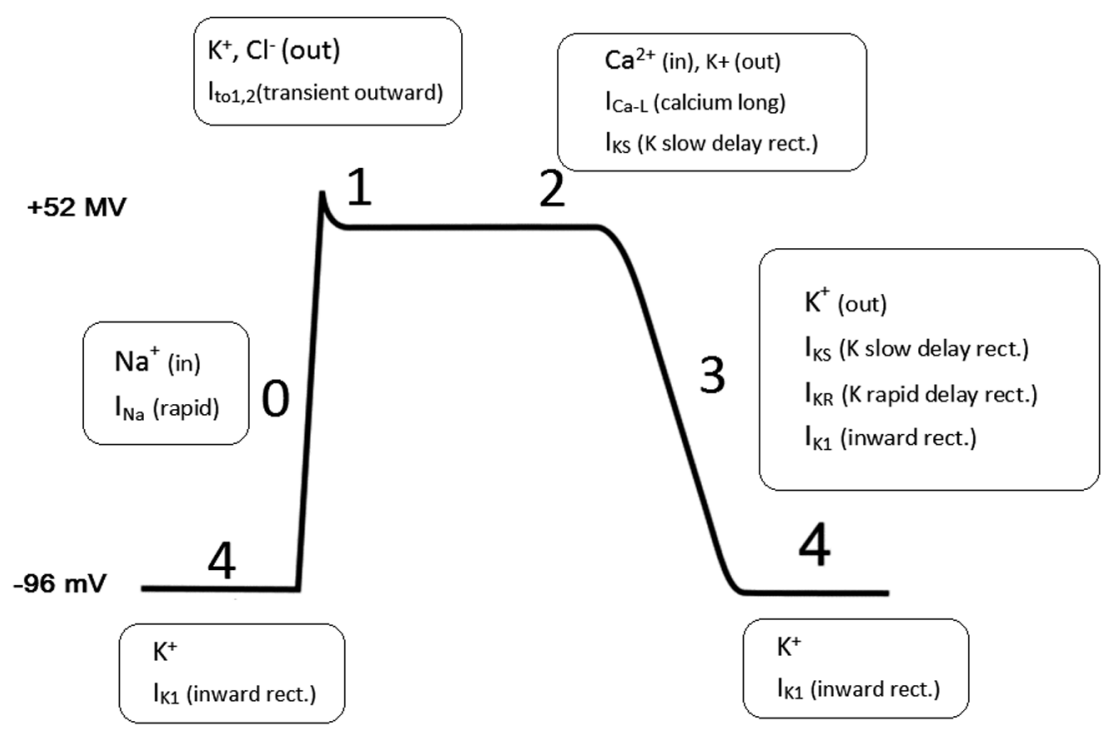

Fig. 2. The monophasic action potential of the myocardial cell is shown. The plateau phase largely depends on the potassium and the calcium ion channel activity. The longer the plateau phase, the more increased the myocardial cell's repolarization. 
when the main clinical characteristics of diastolic heart failure and high-output heart failure usually appear. The decrease of systolic ventricular competence may enhance the development of complications, such as sodium and water-retention, ascites formation and worsening of the kidney function [53].

\section{Laboratory markers}

The determination of natriuretic peptides plays an important role in the diagnosis of heart failure. Atrial natriuretic peptide (ANP) is released from the atrial myocardium due to intracardiac volume overload. Consequently, atrial wall stretch is augmented resulting in higher serum levels of this biomarker. Since decompensated cirrhosis eventuates altered intracardiac volume and pressure conditions, ANP is likely to be elevated in these particular cases $[54,55]$. Brain natriuretic peptide (BNP) and its pro-hormone (pro-BNP) are useful in the diagnosis of myocardial injury, and have been shown to be elevated in patients with cirrhosis. Moreover, these correlate with the stage of the liver disease and may show the severity of myocardial dysfunction and ventricular hypertrophy. Despite these favorable features BNP and pro-BNP may not be able to indicate the hyperdynamic circulation $[56,57]$. These biomarkers have also been shown to be helpful in the screening of CCM [58]. Another laboratory marker, high sensitive troponin I seems to be valuable in the risk stratification of patients undergoing transjugular intrahepatic portosystemic shunts [59]. Recently, a novel plasma biomarker, the galectin-3 has been shown to mediate myocardial fibrosis and to be expressed in cirrhosis. Furthermore, galectin-3 binding protein concentrations have also been found to be increased in patients with cirrhosis [60].

\section{Echocardiography}

\section{Assessment of systolic function}

The left ventricular systolic performance highly depends upon its contractility. Additionally, ventricular pre- and afterload, and heart rate have an influence on the myocardial contractile power. The ejection fraction (EF) is known to be the best marker of the left ventricular systolic function. It is known to be a predictor of cardiovascular outcomes, including sudden cardiac death in patients with symptomatic heart failure [61]. For the evaluation of ejection fraction linear measurements (Teicholz or Quinones) can be performed by means of a two-dimensional echocardiography [62]. These methods require certain geometric assumptions, therefore they are not recommended to be used in the everyday clinical practice. Instead, the ejection fraction can be calculated more exactly from the difference between the end-diastolic and the end-systolic left ventricular volume, divided by the enddiastolic volume (Simpson's method) [63] (Fig. 3). Finally, speckle tracking, another echocardiographic method evaluates the frame-to frame tracking of the ventricular myocardium in radial, circumferential and longitudinal axis. This can provide a sensitive description of left ventricular systolic function [64]. Furthermore, new research is going on with the development of new techniques related to echocardiography, which in the future will improve this diagnostic method. Finally, radionuclide scintigraphy (MUGA - Multi Gated Acquisition
Scan) can provide highly reliable values of left ventricular ejection fraction when echocardiography is uncertain [65].

\section{Evaluation of diastolic function}

Left ventricular relaxation abnormalities may be diagnosed with echocardiography, too. Even the asymptomatic diastolic dysfunction can be recognized at an early disease stage and therapy can be started without delay. Moreover, another echocardiographic entity, isolated diastolic dysfunction (heart failure with normal ejection fraction) can be recognized. For the evaluation of diastolic function the transmitral flow velocities are measured in early diastole and late diastole (presystole) with the help of a pulsed wave Doppler technique. The early diastolic transmitral peak flow velocity (E) can be determined from the apical four-chamber view. The peak flow velocity in the late diastolic period during the atrial contraction (A) is also determined. The time between the peak and the end of the E-wave deceleration slope is defined as deceleration time (DT) [66] (Fig. 4). Using Tissue Doppler Imaging (TDI) the

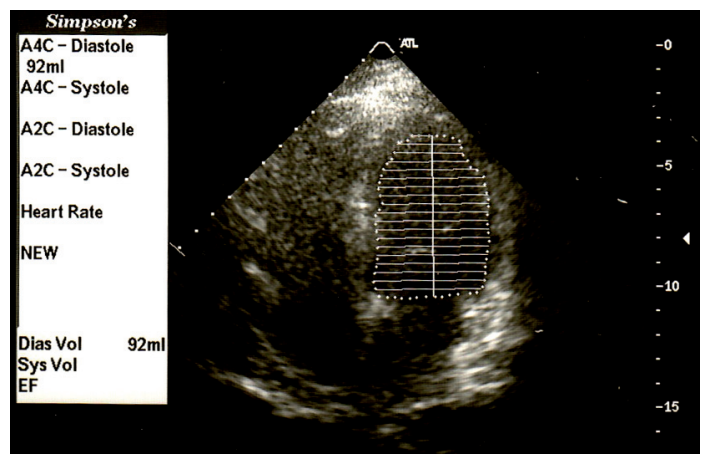

Fig. 3. Evaluation of the left ventricular systolic function by means of echocardiography during volumetric measurements. The determination of the left ventricular diastolic volume from the four-chamber apical view (Simpson's method) is shown.

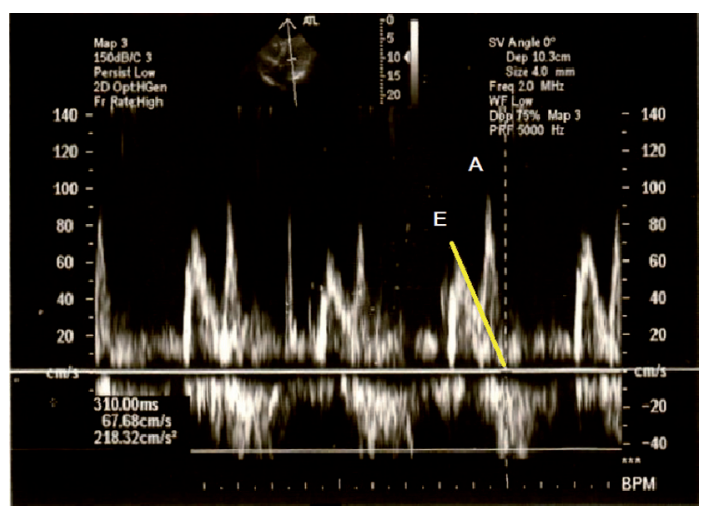

Fig. 4. Transmitral flow velocities measured with the help of a pulsed-wave Doppler technique. The ratio of early diastolic peak velocity (E) and late diastolic velocity (A) is less than 1 . The deceleration time (DT) lasts from the peak till the end of the E-wave (shown in yellow). It is measured to be lengthened $(310 \mathrm{msec})$. These data suggest a diastolic dysfunction (relaxation disorder). In patients with cirrhosis $\mathrm{E} / \mathrm{A}$ ratio is usually markedly reduced $(\mathrm{E} / \mathrm{A}<1)$ and the deceleration time is prolonged (DT $>240 \mathrm{msec}$ ). 
early diastolic velocity of the septal mitral annulus (Ea) from the apical approach can be examined. In order to estimate the left ventricular filling pressure the ratio of the $\mathrm{E}$ and $\mathrm{Ea}(\mathrm{E} /$ $\mathrm{Ea}$ ) is also calculated. First degree (mild) diastolic dysfunction (DD) is defined as: $\mathrm{E} / \mathrm{A}<0.8, \mathrm{E} / \mathrm{Ea}<8, \mathrm{DT}>200 \mathrm{msec}$ and second degree (medium) DD as: $0.8<\mathrm{E} / \mathrm{A}<1.5,8<\mathrm{E} / \mathrm{Ea}<$ 13 and the DT is $160-200 \mathrm{msec}$. The criteria for third degree (severe) DD are: E/A > 2, E/Ea > 13, DT < $160 \mathrm{msec}[67,68]$. The diastolic dysfunction in cirrhosis is most pronounced in patients with ascites $[28,53]$.

\section{Electrocardiography}

The evaluation of the 12-lead surface electrocardiogram of patients with cirrhosis is useful in the recognition of pulse generation and/or conduction disturbances, and cardiac arrhythmia markers can also be examined. The QT interval is one of the most important electrocardiographic parameters for the description of ventricular repolarization in patients with cirrhosis. Numerous diseases may result in the prolongation of this arrhythmia marker (amyloidosis, sarcoidosis, carcinoid, hemochromatosis, diabetes mellitus, thyroid dysfunction or Parkinson's disease) [69-74]. In addition, the QT interval may be affected by genetic causes (long QT syndrome, short QT syndrome). The prolongation of the QT interval may be the consequence of drug interaction (e.g. haloperidol, methadone, amiodarone, sotalol, selective serotonin reuptake inhibitors, macrolide antibiotics, antifungal agents) [75]. Since this repolarization marker may be affected by various causes, the clarification of the patient's history is one of the key points in the arrhythmia risk determination.

Considering the required standards for precision, measurement of the QT interval still remains subjective because the end of the $T$ wave cannot always be exactly defined [76]. QT interval may be measured manually by using the threshold method, where the end of the $\mathrm{T}$ wave is the point at which the $\mathrm{T}$ wave intercepts the isoelectric line. During the tangent method the end of the $\mathrm{T}$ wave is determined by the intersection of a line determined from the tangent line and the isoelectric line. The tangent line is defined as the terminal part of the T wave at the point of maximum downslope [77]. In order to get more exact data, three consecutive sections can be defined, then their average is calculated and the resulting value used as the QT interval in the given electrocardiographic lead (Fig. 5). The QT interval depends on the ventricular rate (the faster the heart rate the shorter the QT interval). Therefore the QT interval should be corrected to the heart rate (QTc). There are numerous methods that may provide the correction of this parameter. Bazett's formula is one of the most important in this field $(\mathrm{QTc}=\mathrm{QT} / \sqrt{\mathrm{RR}})[78]$. The QTc $>450 \mathrm{msec}$ value shows an increased risk of ventricular arrhythmias [79]. Interestingly, in patients with cirrhosis this formula does not clearly describe the relationship between the QT and heart rate. Therefore a specific 'cirrhosis formula' has been derived, which is similar to the Friderica's, and can be confidently used in this setting [80]. In order to eliminate the inter-observer variability, during the manual measurements values may be calculated with calipers by one examiner [40].

\section{THERAPEUTIC APPROACH TO CIRRHOTIC CARDIOMYOPATHY}

Impaired cardiac output in patients with CCM may result in an altered renal perfusion contributing to the pathogenesis of the hepatorenal syndrome.

In addition, due to the decrease in cardiac output, the sympathetic tone increases contributing to the activation of renal sodium and water retention, and also to the activation of the RAAS. Diastolic myocardial dysfunction can contribute to an elevated ventricular pressure. The consequently decreased circulatory volume can cause a further increase in sodium retention. Therefore, the increased sodium excretion mainly through aldosterone-blockers and diuretics can result in an improved cardiac function. As of now, no generally accepted protocol and clinical trials on the management of CCM are available. Consequently, patients should be treated following the guidelines for non-cirrhosis induced heart failure [2].

\section{Angiotensin converting enzyme (ACE) inhibitors}

Patients with cirrhosis on ACE inhibitor therapy could attain long term clinical benefits, but currently no studies are available to prove their efficacy in CCM. According to the latest

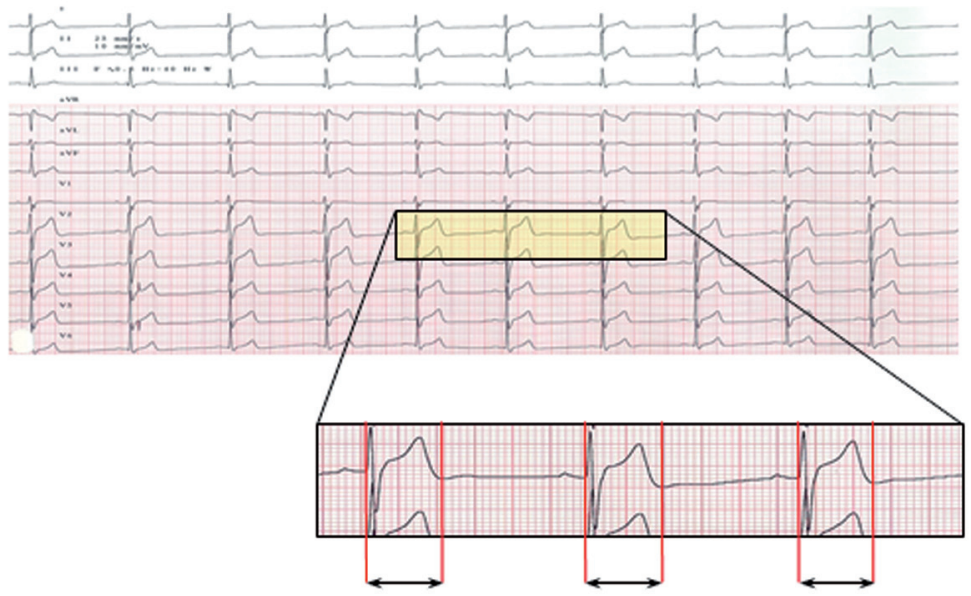

Fig. 5. The manual measurement of the QT interval of the 12-lead surface electrocardiogram. The calculation and averaging of three consecutive sections may provide a more accurate result in the given lead. 
guideline, ACE inhibitors should be administered in patients with heart failure, unless contraindicated, in order to reduce morbidity and mortality. Data obtained from previous clinical investigations have shown no differences regarding clinical symptoms and survival among available ACE inhibitors. Management should be started at low doses, with gradual dose increments. Renal function and serum potassium should be monitored periodically especially in patients with renal impairment. It is also important to know that ACE inhibitor administration in patients with Child Pugh A cirrhosis is safe, but not in more severe stages, due to the reduction in glomerular filtration rate $[81,82]$.

\section{Angiotensin-II receptor blockers}

Though angiotensin receptor blockers (ARB) have been shown to increase sodium excretion without significantly affecting renal and systemic hemodynamics, they have not yielded beneficial clinical effects in long-term management of patients with cirrhosis [83].

\section{Loop and thiazide diuretics}

Only diuretics can effectively control the fluid retention of patients suffering from heart failure. Therefore, the appropriate administration of these drugs is one of the key elements of the treatment of these individuals, while inappropriately low doses will result in a fluid retention. On the other hand, the incautious use of high doses can lead to hypovolemia, hypotension and kidney failure. Loop diuretics (e.g. furosemide) are considered to be the diuretic agents for most patients with heart failure. Thiazide diuretics may be useful in hypertensive patients with the symptoms of moderate fluid retention since their administration results in a more pronounced antihypertensive effect [81].

\section{Aldosterone receptor antagonists}

Hyperaldosteronism is present in nearly all patients with cirrhosis and heart failure. Aldosterone may have various harmful effects on the myocardium and the cardiovascular system [16]. Consequently, mineralocorticoid receptor antagonists may be among the first choices of therapy [84]. They can improve the hemodynamic properties of patients with cirrhosis and may decrease the severe symptoms of heart failure [85]. According to the data obtained from the RALES (Randomized Aldactone Evaluation Study) trial, a 30\% reduction in all-cause mortality and a reduced risk of sudden cardiac death can be reached with the use of spironolactone in patients with chronic heart failure (left ventricular EF $<35 \%$ ) [86]. The selective aldosterone blocker, eplerenone has also been shown to reduce cardiovascular deaths and hospitalizations due to heart failure in a wider range of patients [87]. Therefore, aldosterone receptor antagonists are useful therapeutic tools in the management of patients with symptomatic heart failure and reduced left ventricular ejection fraction. Importantly, the careful monitoring of serum potassium and renal function can help to avoid the danger of hyperkalemia and renal insufficiency. A beneficial effect of the aldosterone antagonist, $\mathrm{K}$-canrenoate has been shown to reverse myocardial fibrosis in patients with pre-ascitic cirrhosis $[81,88]$.

\section{Beta-receptor blockers}

The beta-adrenoceptor blockers, especially the nonselective ones (propranolol, nadolol) are effective in reducing portal hypertension and thus in the prevention of the gastroesophageal bleeding. More recently, carvedilol - a vasodilator, non-selective beta-blocker (NSBB) with intrinsic anti-alfa adrenergic activity - has been reported to have greater effect on decreasing portal hypertension than propranolol or nadolol. Additionally, beta-blockers can improve the cardiac contractile function $[89,90]$. At the same time, no studies on beta-blockers for CCM are available so far. Beta-receptor blockers may be one of the choices of treatment since more trials showed their effectiveness in the reduction of mortality in patients with systolic heart failure [51, 91]. Bisoprolol, metoprolol succinate and carvedilol have been proven to be the most effective in this field. Due to the beneficial effect of carvedilol on portal hypertension, this agent could be the first consideration in CCM [81]. Furthermore, long-term treatment with beta-blockers can decrease the symptoms of heart failure, and improve the patient's clinical status. Management with beta-blockers should be initiated at low doses, and patients should be carefully monitored, since therapy may result in fluid retention and worsening heart failure, bradycardia, pulse conduction abnormalities and hypotension. Even if symptoms do not improve, long-term treatment should be maintained in order to reduce cardiovascular mortality $[81,92]$. In addition, NSBBs have been proven to restore lengthened QT intervals towards normal in patients with cirrhosis [51]. Despite all these beneficial clinical data currently no definitive recommendation for the chronic administration of beta-blockers can be made in patients with cirrhosis.

Transjugular intrahepatic portosystemic shunt (TIPS)

Since TIPS can rapidly shift a significant amount of blood from the splanchnic area to the heart, it may result in a sudden worsening of the cardiac function in patients with cirrhosis, especially in individuals with impaired diastolic function [93].

\section{Liver transplantation}

Liver transplantation is known to be a solution for liver failure due to cirrhosis. Interestingly, it seems to cure the associated cardiomyopathy as well [20]. Previously, amelioration of left ventricular hypertrophy, diastolic (lusitropic) dysfunction and normalization of the contractile function after transplantation have been reported [7]. Prolonged QTc has also been shown to be reversible by liver transplantation, despite remaining lengthened right after the surgery [94]. On the contrary, orthotropic liver transplantation may cause severe hemodynamic consequences, since it can result in an abrupt decrease in cardiac output due to the clamping of the inferior vena cava. Moreover, a post reperfusion injury, secondary coagulopathy, and post-operative hydrostatic pulmonary edema may worsen the clinical outcome [95]. In addition, cirrhotic patients with concomitant severe cardiomyopathy may benefit from cardiac transplantation [96].

\section{Farnesoid $\mathrm{X}$ receptor agonists}

Novel therapeutic attempts are aiming to increase the intrahepatic concentration of vasodilators. Farnesoid X 
receptor agonists are responsible for hydrogen sulfide production; moreover, NCX-1000 may release NO in the liver [97]. These agents are promising for future therapeutic regimens but their exact role is not yet elucidated in CCM.

\section{CONCLUSIONS}

Currently, there is no single diagnostic tool that can help to identify patients with CCM. Patients with symptoms of heart failure suffering from cirrhosis should undergo a cardiac screening to clarify the structural and functional properties of the heart. We emphasize that an early recognition of systolic or diastolic myocardial dysfunction by means of echocardiography may help to prevent the patient from further worsening of his/ her clinical status. Furthermore, electrocardiography can help to recognize the increased risk for arrhythmias and sudden cardiac death. Natriuretic peptides may attract attention to the altered intracardiac pressure and volume conditions, while novel laboratory markers may reflect cardiac and hepatic fibrosis. Evidence for cardiomyopathy should be suspected in patients with worsening symptoms and clinical results, who may benefit from a proper treatment of the underlying pathology. At present the management of CCM should follow the recommendations for the treatment of patients with heart failure. Further investigations may help to improve our knowledge on cardiac consequences of liver diseases.

Author contributions: All authors contributed to the design, drafting and final approval/preparation of the article.

Conflicts of interest: None to declare.

Acknowledgement: Supported by Janos Bolyai Research Scholarship of the Hungarian Academy of Sciences and Internal Research Grant of University of Debrecen.

\section{REFERENCES}

1. Henriksen JH, Moller S. Cardiac and systemic haemodynamic complications of liver cirrhosis. Scand Cardiovasc J 2009;43:218-225.

2. Wong F. Cirrhotic cardiomyopathy. Hepatol Int 2009;3:294-304.

3. Zardi EM, Abbate A, Zardi DM, et al. Cirrhotic cardiomyopathy. J Am Coll Cardiol 2010;56:539-549.

4. Mikulic E, Munoz C, Puntoni LE, Lebrec D. Hemodynamic effects of dobutamine in patients with alcoholic cirrhosis. Clin Pharmacol Ther 1983;34:56-59.

5. Fitzgibbons TP, Meyer TE, Aurigemma GP. Mortality in diastolic heart failure: an update. Cardiol Rev 2009;17:51-55.

6 Rosenberg MA, Manning WJ. Diastolic dysfunction and risk of atrial fibrillation: a mechanistic appraisal. Circulation 2012;126:2353-2362.

7. Torregrosa M, Aguade S, Dos L, et al. Cardiac alterations in cirrhosis: reversibility after liver transplantation. J Hepatol 2005;42:68-74.

8. Moller S, Hove JD, Dixen U, Bendtsen F. New insights into cirrhotic cardiomyopathy. Int J Cardiol 2013;167:1101-1108.

9. Moller S, Henriksen JH. Cardiovascular complications of cirrhosis. Postgrad Med J 2009;85:44-54.

10. Henriksen JH, Siemssen O, Krintel JJ, Malchow-Moller A, Bendtsen F, Ring-Larsen H. Dynamics of albumin in plasma and ascitic fluid in patients with cirrhosis. J Hepatol. 2001;34:53-60.
11. Schrier RW, Ecder T. Gibbs memorial lecture. Unifying hypothesis of body fluid volume regulation: implications for cardiac failure and cirrhosis. Mt Sinai J Med 2001;68:350-361.

12. Moller S, Henriksen JH, Bendtsen F. Central and noncentral blood volumes in cirrhosis: relationship to anthropometrics and gender. Am J Physiol Gastrointest Liver Physiol 2003;284:G970-G979.

13. Liu H, Ma Z, Lee SS. Contribution of nitric oxide to the pathogenesis of cirrhotic cardiomyopathy in bile duct-ligated rats. Gastroenterology 2000;118:937-944.

14. Gaskari SA, Liu H, Moezi L, Li Y, Baik SK, Lee SS. Role of endocannabinoids in the pathogenesis of cirrhotic cardiomyopathy in bile duct-ligated rats. Br J Pharmacol 2005;146:315-323.

15. Iwakiri Y, Groszmann RJ. The hyperdynamic circulation of chronic liver diseases: from the patient to the molecule. Hepatology 2006;43(2 Suppl 1):S121-S131.

16. Schrier RW. Water and sodium retention in edematous disorders: role of vasopressin and aldosterone. Am J Med 2006;119(7 Suppl 1):S47-S53.

17. Moller S, Henriksen JH. Cardiovascular complications of cirrhosis. Gut 2008;57:268-278.

18. Bernardi M. Cirrhotic cardiomyopathy. Clin Liver Dis 2013;2:99-101.

19. Krag A, Bendtsen F, Mortensen C, Henriksen JH, Moller S. Effects of a single terlipressin administration on cardiac function and perfusion in cirrhosis. Eur J Gastroenterol Hepatol 2010;22:1085-1092.

20. Myers RP, Lee SS. Cirrhotic cardiomyopathy and liver transplantation. Liver Transpl 2000;(4 Suppl 1):S44-S52.

21. Arroyo V, Terra C, Gines P. Advances in the pathogenesis and treatment of type-1 and type-2 hepatorenal syndrome. J Hepatol 2007;46:935-946.

22. Salerno F, Gerbes A, Gines P, Wong F, Arroyo V. Diagnosis, prevention and treatment of hepatorenal syndrome in cirrhosis. Postgrad Med J 2008;84:662-670.

23. Ceolotto G, Papparella I, Sticca A, et al. An abnormal gene expression of the beta-adrenergic system contributes to the pathogenesis of cardiomyopathy in cirrhotic rats. Hepatology 2008;48:1913-1923.

24. Ma Z, Lee SS, Meddings JB. Effects of altered cardiac membrane fluidity on beta-adrenergic receptor signalling in rats with cirrhotic cardiomyopathy. J Hepatol 1997;26:904-912.

25. Szabo Z, Harangi M, Lorincz I, et al. Effect of hyperlipidemia on QT dispersion in patients without ischemic heart disease. Can J Cardiol 2005;21:847-850.

26. Anselmi A, Gaudino M, Baldi A, et al. Role of apoptosis in pressureoverload cardiomyopathy. J Cardiovasc Med (Hagerstown) 2008;9:227232.

27. Herring N, Danson EJF, Paterson DJ. Cholinergic control of heart rate by nitric oxide is site specific. News Physiol Sci 2002;17:202-206.

28. Finucci G, Desideri A, Sacerdoti D, et al. Left ventricular diastolic function in liver cirrhosis. Scand J Gastroenterol 1996;31:279-284.

29. Patel BM, Mehta AA. Aldosterone and angiotensin: Role in diabetes and cardiovascular diseases. Eur J Pharmacol 2012;697:1-12..

30. Gundling F, Schmidtler F, Zelihic E, et al. Frequency of cardiac arrhythmia in patients with liver cirrhoses and evaluation of associated factors. Z Gastroenterol 2012;50:1149-1155.

31. Rigolli M, Whalley GA. Heart failure with preserved ejection fraction. J Geriatr Cardiol 2013;10:369-376.

32. Bernardi M, Calandra S, Colantoni A, et al. Q-T interval prolongation in cirrhosis: prevalence, relationship with severity, and etiology of the disease and possible pathogenetic factors. Hepatology 1998;27:28-34.

33. Henriksen JH, Fuglsang S, Bendtsen F, Christensen E, Moller S. Dyssynchronous electrical and mechanical systole in patients with cirrhosis. J Hepatol 2002;36:513-520. 
34. Zambruni A, Trevisani F, Caraceni P, Bernardi M. Cardiac electrophysiological abnormalities in patients with cirrhosis. J Hepatol 2006;44:994-1002.

35. Day CP, James OF, Butler TJ, Campbell RW. QT prolongation and sudden cardiac death in patients with alcoholic liver disease. Lancet 1993;341:1423-1428.

36. Lazzeri C, La Villa G, Laffi G, et al. Autonomic regulation of heart rate and QT interval in nonalcoholic cirrhosis with ascites. Digestion 1997;58:580-586.

37. Bernardi M, Rubboli A, Trevisani F, et al. Reduced cardiovascular responsiveness to exercise-induced sympathoadrenergic stimulation in patients with cirrhosis. J Hepatol 1991;12:207-216.

38. Goldenberg I, Moss AJ, Zareba W. QT interval: how to measure it and what is "normal". J Cardiovasc Electrophysiol 2006;17:333-336.

39. Lőrincz I, Kun C, Szabó Z. QT dispersion - clinical significance - past, present, future. Acta Physiol Hung 2002;89:138.

40. Malik M, Batchvarov VN. Measurement, interpretation and clinical potential of QT dispersion. J Am Coll Cardiol 2000;36:1749-1766.

41. Meyer JS, Mehdirad A, Salem BI, Kulikowska A, Kulikowski P. Sudden arrhythmia death syndrome: importance of the long QT syndrome. Am Fam Physician $2003 ; 68: 483-488$.

42. Baik SK, Fouad TR, Lee SS. Cirrhotic cardiomyopathy. Orphanet J Rare Dis 2007;2:15

43. Trevisani F, Merli M, Savelli F, et al. QT interval in patients with noncirrhotic portal hypertension and in cirrhotic patients treated with transjugular intrahepatic porto-systemic shunt. J Hepatol 2003;38:461467.

44. Ward CA, Ma Z, Lee SS, Giles WR. Potassium currents in atrial and ventricular myocytes from a rat model of cirrhosis. Am J Physiol 1997;273:G537-G544.

45. Ward CA, Liu H, Lee SS. Altered cellular calcium regulatory systems in a rat model of cirrhotic cardiomyopathy. Gastroenterology 2001;121:1209-1218.

46. Antzelevitch C, Shimizu W, Yan GX, Sicouri S. Cellular basis for QT dispersion. J Electrocardiol 1998;30 Suppl:168-175.

47. Moreau R, Komeichi H, Kirstetter P, Ohsuga M, Cailmail S, Lebrec D. Altered control of vascular tone by adenosine triphosphatesensitive potassium channels in rats with cirrhosis. Gastroenterology 1994;106:1016-1023.

48. Wiest R, Das S, Cadelina G, Garcia-Tsao G, Milstien S, Groszmann RJ. Bacterial translocation in cirrhotic rats stimulates eNOS-derived NO production and impairs mesenteric vascular contractility. J Clin Invest 1999;104:1223-1233.

49. Wiese S, Mortensen C, Gotze JP, et al. Cardiac and proinflammatory markers predict prognosis in cirrhosis. Liver Int 2013 Dec 7.

50. Salter KJ, Kozlowski RZ. Differential electrophysiological actions of endothelin-1 on $\mathrm{Cl}$ - and $\mathrm{K}+$ currents in myocytes isolated from aorta basilar and pulmonary artery. J Pharmacol Exp Ther 1998;284:11221231.

51. Henriksen JH, Bendtsen F, Hansen EF, Moller S. Acute non-selective beta-adrenergic blockade reduces prolonged frequency-adjusted. J Hepatol 2004;40:239-246.

52. Zambruni A, Trevisani F, Di Micoli A, et al. Effect of chronic betablockade on QT interval in patients with liver cirrhosis. J Hepatol 2008;48:415-421.

53. Pozzi M, Carugo S, Boari G, et al. Evidence of functional and structural cardiac abnormalities in cirrhotic patients with and without ascites. Hepatology 1997;26:1131-1137.
54. Rector WG Jr, Adair O, Hossack KF, Rainguet S. Atrial volume in cirrhosis: relationship to blood volume and plasma concentration of atrial natriuretic factor. Gastroenterology 1990;99:766-770.

55. Gerbes AL, Wernze H, Arendt RM, Riedel A, Sauerbruch T, Paumgartner $\mathrm{G}$. Atrial natriuretic factor and renin-aldosterone in volume regulation of patients with cirrhosis. Hepatology 1989;9:417-422.

56. Wong F, Siu S, Liu P, Blendis LM. Brain natriuretic peptide: is it a predictor of cardiomyopathy in cirrhosis? Clin Sci (Lond)2001;101:621628.

57. Henriksen JH, Gotze JP, Fuglsang S, Christensen E, Bendtsen F, Moller S. Increased circulating pro-brain natriuretic peptide (proBNP) and brain natriuretic peptide (BNP) in patients with cirrhosis: relation to cardiovascular dysfunction and severity of disease. Gut 2003;52:15111517.

58. Potter LR, Yoder AR, Flora DR, Antos LK, Dickey DM. Natriuretic peptides: their structures, receptors, physiologic functions and therapeutic applications. Handb Exp Pharmacol 2009;191:341-366.

59. Pateron D, Beyne P, Laperche T, et al. Elevated circulating cardiac troponin I in patients with cirrhosis. Hepatology 1999;29:640-643.

60. Wanninger J, Weigert J, Wiest R, et al. Systemic and hepatic vein galectin-3 are increased in patients with alcoholic liver cirrhosis and negatively correlate with liver function. Cytokine 2011;55:435-440.

61. Curtis JP, Sokol SI, Wang Y, et al. The association of left ventricular ejection fraction, mortality, and cause of death in stable outpatients with heart failure. J Am Coll Cardiol 2003;42:736-742.

62. Wilson DJ, North N, Wilson RA. Comparison of Left Ventricular Ejection Fraction Calculation Methods. Echocardiography 1998;15:709712.

63. Otterstad JE. Measuring left ventricular volume and ejection fraction with the biplane Simpson's method. Heart 2002;88:559-560.

64. Mondillo S, Galderisi M, Mele D, et al. Speckle-tracking echocardiography: a new technique for assessing myocardial function. J Ultrasound Med 2011;30:71-83.

65. Ishibashi M, Yoshioka F, Umezaki N, Morita S. Assessment of cardiac function using radionuclide techniques--theory, technica considerations and clinical application. Kurume Med J 1991;38:93-107.

66. Little WC, Warner JG Jr, Rankin KM, Kitzman DW, Cheng CP. Evaluation of left ventricular diastolic function from the pattern of left ventricular filling. Clin Cardiol 1998;21:5-9.

67. Denes M, Kiss I, Lengyel M. Assessment of diastolic dysfunction in elderly hypertensive patients using integrated Doppler echocardiography Blood Press 2009;18:135-141.

68. Nagueh SF, Appleton CP, Gillebert TC, et al. Recommendations for the evaluation of left ventricular diastolic function by echocardiography. Eur J Echocardiogr 2009;10:165-193.

69. Gilotra NA, Chow GV, Cingolani OH. Cardiac amyloidosis presenting with prolonged QT interval and recurrent polymorphic ventricular tachycardia. Tex Heart Inst J 2013;40:193-195.

70. Uyarel H, Uslu N, Okmen E, et al. QT dispersion in sarcoidosis. Chest 2005;128:2619-2625.

71. Fox DJ, Khattar RS. Carcinoid heart disease: presentation, diagnosis, and management. Heart 2004;90:1224-1228.

72. Lee NR, Park JH, Rhee KS. Acquired long QT syndrome and sudden cardiac death due to secondary hemochromatosis with multitransfusions for severe aplastic anemia. Ann Hematol 2008;87:933-935.

73. Cardoso C, Salles G, Bloch K, Deccache W, Siqueira-Filho AG. Clinical determinants of increased QT dispersion in patients with diabetes mellitus. Int J Cardiol 2001;79:253-262. 
74. Ishizaki F, Harada T, Yoshinaga H, Nakayama T, Yamamura Y, Nakamura S. Prolonged QTc intervals in Parkinson's disease-relation to sudden death and autonomic dysfunction. No To Shinkei 1996;48:443448.

75. Yap YG, Camm J. Risk of torsades de pointes with non-cardiac drugs. Doctors need to be aware that many drugs can cause qt prolongation. BMJ 2000 ;320:1158-1159.

76. Panicker GK, Karnad DR, Joshi R, et al. Z-score for benchmarking reader competence in a central ECG laboratory. Ann Noninvasive Electrocardiol 2009;14:19-25.

77. Panicker GK, Karnad DR, Natekar M, Kothari S, Narula D, Lokhandwala Y. Intra- and interreader variability in QT interval measurement by tangent and threshold methods in a central electrocardiogram laboratory. J Electrocardiol 2009;42:348-352.

78. Bazett HC. An analysis of the time-relations of electrocardiograms. Ann Noninvasive Electrocardiol 1997;2:177-194.

79. QTc Prolongation and Risk of Sudden Cardiac Death: Is the Debate Over? Medscape. 2006 Feb 3; http://www.medscape.com/ viewarticle/522879.

80. Moller S, Bernardi M. Interactions of the heart and the liver. Eur Heart J 2013;34:2804-2811.

81. Yancy CW, Jessup M, Bozkurt B, et al. 2013 ACCF/AHA guideline for the management of heart failure: a report of the American College of Cardiology Foundation/American Heart Association Task Force on Practice Guidelines. J Am Coll Cardiol 2013;62:e147-e239.

82. Tsochatzis EA, Bosch J, Burroughs AK. New therapeutic paradigm for patients with cirrhosis. Hepatology 2012;56:1983-1992.

83. Wong F, Liu P, Blendis L. The mechanism of improved sodium homeostasis of low-dose losartan in preascitic cirrhosis. Hepatology 2002;35:1449-1458.

84. Bos R, Mougenot N, Findji L, Mediani O, Vanhoutte PM, Lechat P. Inhibition of catecholamine-induced cardiac fibrosis by an aldosterone antagonist. J Cardiovasc Pharmacol 2005;45:8-13.

85. Schrier RW. Use of diuretics in heart failure and cirrhosis. Semin Nephrol 2011;31:503-512.
86. Vizzardi E, D’Aloia A, Giubbini R, et al. Effect of spironolactone on left ventricular ejection fraction and volumes in patients with class I or II heart failure. Am J Cardiol 2010;106:1292-1296.

87. Zannad F, McMurray JJ, Krum H, et al. Eplerenone in patients with systolic heart failure and mild symptoms. N Engl J Med 2011;364:11-21.

88. Butler J, Ezekowitz JA, Collins SP, et al. Update on aldosterone antagonists use in heart failure with reduced left ventricular ejection fraction. Heart Failure Society of America Guidelines Committee. J Card Fail 2012;18:265-281.

89. Ma Z, Lee SS, Meddings JB. Effects of altered cardiac membrane fluidity on beta-adrenergic receptor signalling in rats with cirrhotic cardiomyopathy. J Hepatol 1997;26:904-912.

90. Bosch J. Carvedilol: the beta-blocker of choice for portal hypertension? Gut 2013;62:1529-1530.

91. Barrese V, Taglialatela M. New advances in beta-blocker therapy in heart failure. Front Physiol 2013;4:323.

92. Exner DV, Dries DL, Waclawiw MA, Shelton B, Domanski MJ. Beta-adrenergic blocking agent use and mortality in patients with asymptomatic and symptomatic left ventricular systolic dysfunction: a post hoc analysis of the Studies of Left Ventricular Dysfunction. J Am Coll Cardiol 1999;33:916-923.

93. Cazzaniga M, Salerno F, Pagnozzi G, et al. Diastolic dysfunction is associated with poor survival in patients with cirrhosis with transjugular intrahepatic portosystemic shunt. Gut 2007;56:869-875.

94. Shin WJ, Kim YK, Song JG, et al. Alterations in QT interval in patients undergoing living donor liver transplantation. Transplant Proc 2011;43:170-173.

95. Moller S, Henriksen JH. Cardiovascular dysfunction in cirrhosis. Pathophysiological evidence of a cirrhotic cardiomyopathy. Scand J Gastroenterol 2001;36:785-794.

96. Hsu RB, Chang CI, Lin FY, et al. Heart transplantation in patients with liver cirrhosis. Eur J Cardiothorac Surg 2008;34:307-312.

97. Fiorucci S, Antonelli E, Brancaleone V, et al. NCX-1000, a nitric oxide-releasing derivative of ursodeoxycholic acid, ameliorates portal hypertension and lowers norepinephrine-induced intrahepatic resistance in the isolated and perfused rat liver. J Hepatol 2003;39:932-939. 